\title{
Poisoning in children 2: Painkillers
}

\section{Riordan, G Rylance, K Berry}

\section{Painkillers and antipyretics are the largest group of toxins encountered by children}

$\mathrm{n}$ this, the second of a series of articles on the management of poisoning, we

deal with the largest group of toxins encountered by children-painkillers and antipyretics.

\section{PARACETAMOL}

Children are more resistant to paracetamol induced liver damage than adults. Chronic overdosage is more likely to result in harm than the acute effects of ingestion. Special care should be taken with children who are malnourished or on cytochrome P450 enzyme inducing drugs.

Toxic paracetamol concentrations associated with the accidental ingestion of paracetamol suspension are extremely rare. A careful history can often obviate the need for investigation or treatment. The volume, and paracetamol concentration, of the formulation should be established from the packaging. The volume remaining should be measured. No allowance should be made for spillage during the course of the accident or poor parental recall as to the amount remaining in the bottle prior to ingestion. In this way, the maximum possible dose of paracetamol consumed can usually be established. If the potential dose of paracetamol consumed can be established with absolute certainty as being below $150 \mathrm{mg} / \mathrm{kg}$, no further action is required.

Where deliberate ingestion is reported or suspected, or the dose accidentally ingested cannot be confirmed, the blood paracetamol concentration should be measured. Paracetamol concentration must be measured at least four hours following ingestion. Samples taken prior to this may be unreliable because of the possibility of continuing absorption and changing drug distribution.

Paracetamol concentration should be compared with the standard adult normogram to determine the need for treatment. A lower treatment threshold $(50 \%$ of the standard concentration at which treatment would be instigated) is recommended for patients in high risk groups. Children at high risk include those who are malnourished (for example, anorexia, failure to thrive) or on cytochrome p450 enzyme inducing drugs.

Patients who have taken a staggered overdose or who present more than eight hours post-ingestion should be started on treatment without waiting for the paracetamol concentration to be reported. Paracetamol concentrations are unreliable when measured more than 15 hours post-ingestion and a full course of treatment is required. Patients taking a staggered overdose should also receive a full course of treatment regardless of their paracetamol concentration at presentation.

Treatment is with intravenous infusion of $\mathrm{N}$-acetylcysteine. Adverse reactions to $\mathrm{N}$-acetylcysteine have been reported but are rare in practice. Mild symptoms can be treated symptomatically and the rate of infusion decreased if necessary. More severe reactions require specialist advice and oral methionine may be considered. All patients require baseline measurements of electrolytes, creatinine, liver enzymes, and coagulation parameters at the onset of treatment. Urinalysis should be performed, as renal tubular damage is associated with paracetamol toxicity. ${ }^{2}$

Provided that baseline results are within the normal range, the same investigations need repeating daily for a minimum of 48 hours post-ingestion. Normal results at 48 hours exclude hepatic damage.

Abnormal results should prompt further, more frequent, measurements and discussion with a paediatric hepatology centre. Patients with severe hepatocellular damage may benefit from protracted administration of low dose $\mathrm{N}$-acetylcysteine $\quad(6.25 \mathrm{mg} / \mathrm{kg} / \mathrm{h}){ }^{3}$ Alanine transaminase activity exceeding $1000 \mathrm{IU} / \mathrm{l}$ is a marker of significant liver injury, but levels are not prognostic. Serial measurements of prothrombin time (international normalised ratio, INR) can provide important information as to residual liver function.

Paediatric guidelines for acute paracetamol ingestion are based on experience in adult practice. The validity of this extrapolation is questionable. Children seem less sensitive to the hepatotoxic effects of paracetamol than are adults. ${ }^{1}$ Possible explanations for this include metabolic differences ${ }^{4}$ and a greater propensity to vomit following acute ingestion. ${ }^{5}$ In addition, almost $80 \%$ of children consume a liquid paediatric paracetamol preparation (see fig 1).

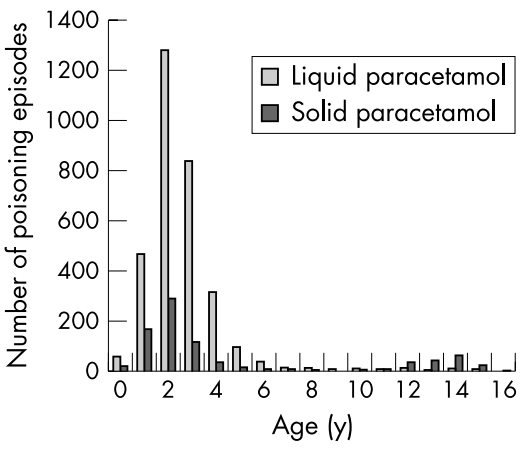

Figure 1 Comparison of age distributions for liquid and solid paracetamol preparations consumed by under $16 \mathrm{~s}^{7}$

These preparations contain low doses of paracetamol, and toxic paracetamol levels are extremely rare following their ingestion. Bond et al have even suggested that paracetamol levels need only be performed if tablets or adult strength preparations are consumed. ${ }^{6}$

\section{NSAIDS}

A large number of different nonsteroidal anti-inflammatory drugs (NSAIDs) are available. Ibuprofen accounts for $65 \%$ of childhood NSAID ingestions, mefanamic acid for $10 \%$, and diclofenac $6 \%$.

As a group these substances are generally of low toxicity, mefanamic acid and phenylbutazone being important exceptions. When consumed in quantity they produce gastrointestinal upset, headache, dizziness, tinnitus, and visual disturbance. Hypotension, tachycardia, and hypothermia have also been reported. Prolongation of the prothrombin time is common. In large overdose electrolyte disturbances, metabolic acidosis, central nervous system depression, and respiratory failure can occur.

Individual NSAIDs have additional idiosyncratic effects in overdose. Ibuprofen may cause bradycardia or hepatic dysfunction. Mefanamic acid is associated with convulsions. Phenylbutazone can cause hepatic failure, arrhythmias, and bone marrow suppression.

Children who have consumed more than $100 \mathrm{mg} / \mathrm{kg}$ of ibuprofen should receive activated charcoal. If they remain asymptomatic, they can be discharged at four hours post-ingestion. If sustained release preparations are consumed, a 12 hour period of observation is advised. Children who have consumed more than $25 \mathrm{mg} / \mathrm{kg}$ of mefanamic acid should receive activated charcoal. They should be observed for 12 hours postingestion. ${ }^{8}$

Symptomatic children require hospital admission. Oral fluids should be encouraged and dehydration corrected. Electrolytes, creatinine, prothrombin time, and acid-base balance should be monitored. Diazepam is the treatment of choice for convulsions. 
Phenylbutazone elimination may be enhanced by use of repeated doses of activated charcoal. Phenylbutazone poisoning is also amenable to treatment with haemoperfusion..$^{9-11}$

\section{COMPOUND ANALGESICS AND OPIOIDS}

Compound analgesics are mixtures of paracetamol or aspirin combined with a variety of opioids and other active ingredients. When assessing overdose of these compounds each active constituent must be considered separately.

In overdose, opioids cause nausea, vomiting, convulsions, central nervous system depression, and respiratory compromise. Dextropropoxyphene may also cause cardiac arrhythmias.

Activated charcoal should be administered if the maximum daily dose of opioid has been exceeded. Asymptomatic children require observation for six hours. Symptomatic children should be admitted to hospital. Management measures for other active ingredients of compound preparations must not be overlooked.

Naloxone, a pure opioid antagonist, effectively reverses opioid induced coma and respiratory depression. Given intravenously its effects are immediate, although its duration of action is short lived (two hours).

Pentazocine and buprenorphine are mixed opioid agonist-antagonists. In overdose they cause dysphoria and less respiratory depression than morphine. Naloxone remains effective in treating coma and respiratory depression caused by these drugs.

Certain adverse effects are induced by mechanisms other than opioid receptor binding. Many opioid drugs cause the release of histamine from mast cells, resulting in hypotension. ${ }^{12}$ This effect will not be reversed by naloxone, and intravenous fluids or inotropes may be required. Dextropropoxyphene acts directly on cardiac tissue to slow inward calcium current and depress myocardial contractility. Experimental data suggest that resulting arrhythmias may not respond to naloxone, ${ }^{13}$ although this remains first line therapy. ${ }^{14}$ Other therapeutic options include sodium bicarbonate, ${ }^{15}$ phenytoin, or atenolol. Class I antiarrhythmic agents should be avoided. ${ }^{8}$

Opioids are also encountered in antimotility drugs, prescribed most frequently for the treatment of diarrhoea. Co-phenotrope (as Lomotil) is the most commonly encountered and the most dangerous. It consists of diphenoxylate, with a small amount of atropine added to discourage abuse. In overdose atropine produces symptoms within a few hours of ingestion. However, the absence of initial anticholinergic symptoms does not exclude significant poisoning. Both drugs delay gastric emptying and symptoms of severe opioid poisoning may be delayed for 24 hours or more. Hospital admission is required if more that the maximum daily therapeutic dose has been ingested. A minimum period of 36 hours observation is recommended Naloxone is an effective antidote. Repeated doses, or an infusion, are likely to be required. Consider gastric decontamination if large quantities of tablets have been consumed.

Loperamide is less toxic. Asymptomatic children who have ingested less than $0.4 \mathrm{mg} / \mathrm{kg}$ are unlikely to require treatment. Symptomatic children should receive treatment with naloxone.

Kaolin and morphine mixture is of moderate toxicity. Doses of less than 10 $\mathrm{ml}$ are unlikely to produce symptoms. Asymptomatic children should be observed for six hours. Naloxone is an effective antidote.

\section{ASPIRIN}

In 1977, Craft and Sibert observed that aspirin accounted for $25 \%$ of all childhood poisonings. ${ }^{16}$ The incidence of salicylate toxicity has declined considerably since the withdrawal of paediatric aspirin preparations from the market in 1986

Salicylates are also encountered in cough and cold powders, topical preparations (for example, Oil of Wintergreen), creams, and wart treatments.

In overdose salicylates stimulate respiration by a direct action on the respiratory centre. In adult patients the ensuing hyperventilation may produce an initial respiratory alkalosis, but this pattern is less common in children. Other symptoms include tinnitus, dizziness, decreased hearing, nausea, and vomiting. Salicylates uncouple oxidative phosphorylation in skeletal muscle, leading to pyrexia and metabolic acidosis. Acidosis enhances transfer of salicylate across the blood-brain barrier. Initial central nervous system stimulation, with excitement or agitation, is followed by respiratory depression and coma.

Asymptomatic children who have consumed less than $120 \mathrm{mg} / \mathrm{kg}$ of aspirin do not require treatment.

Children who have consumed more than $120 \mathrm{mg} / \mathrm{kg}$ of aspirin should receive activated charcoal. Repeated doses may be of some benefit. ${ }^{17} \mathrm{~A}$ plasma salicylate level should be checked at four hours post-ingestion. Blood should also be obtained to check electrolytes, renal function, blood glucose, clotting, and acid-base balance.

Aspirin is poorly soluble in acid and tablets tend to adhere, forming a mass that dissolves slowly. If large numbers of tablets have been consumed, gastric lavage should be considered, up to four hours post-ingestion. In such circumstances, the plasma salicylate level should be repeated at three hourly intervals, until a declining trend is observed, because of the possibility of ongoing absorption

Vomiting, pyrexia, and renal attempts to compensate acid-base disturbance result in significant dehydration. If present, this must be corrected vigorously. Dehydration artificially increases plasma salicylate concentrations and may lead to renal failure.

Children with symptoms other than nausea and vomiting, or evidence of metabolic disturbance, should undergo urinary alkalinisation. These effects are most commonly seen in patients with plasma salicylate concentrations in excess of $400 \mathrm{mg} / \mathrm{l}^{18}$

Salicylate enters the nephron by filtration and proximal tubular secretion. At neutral urine $\mathrm{pH}$ salicylate is extensively reabsorbed in the distal nephron. If the $\mathrm{pH}$ of the distal nephron is raised to more than 7.5, the salicylic acid is trapped in the nephron and drug excretion increases fourfold. ${ }^{19} 20$

Intravenous sodium bicarbonate (1-2 $\mathrm{mmol} / \mathrm{kg} /$ day in maintenance fluid) should be administered. Urine $\mathrm{pH}$ should be maintained above 7.5. Blood $\mathrm{pH}$ and electrolytes should be monitored closely. Because of the reciprocal relation between potassium and hydrogen ions, alkalosis produces hypokalaemia. It can be difficult to achieve adequate urinary alkalinisation when serum potassium is low. Early and adequate intravenous supplementation is important.

In the past forced diuresis was used in combination with urinary alkalinisation. While renal clearance of salicylate increases with urine flow, this effect is diminished as urine $\mathrm{pH}$ rises. ${ }^{19}$ Forced diuresis is no longer recommended.

Patients with unresponsive acidosis, seizures, coma, renal failure, or progressive deterioration should be considered for haemodialysis. These effects are likely to be seen in patients with plasma salicylate concentrations in excess of 700 $\mathrm{mg} / \mathrm{l}$. While haemoperfusion removes salicylate it fails to restore metabolic and fluid homoeostasis, and is not recommended.

\section{SEEKING FURTHER ADVICE}

Specific, expert advice on all aspects of poisoning is available to medical professionals in the United Kingdom via the National Poisons Information Service (NPIS). The regional centres that make up this service have recently introduced a single national enquiry number: 08706006266

A wide range of easily accessible and highly practical advice is available through the NPIS website. ${ }^{21}$ This free service is restricted to medical professionals. On line registration is available at http://www.spib.axl.co.uk/toxbase/.

Arch Dis Child 2002;87:397-399 


\section{Authors' affiliations}

M F Riordan, Department of Pediatrics, Yale University Medical School, USA

G W Rylance, Department of General

Paediatrics, Royal Victoria Infirmary, Newcastle upon Tyne, UK

K Berry, Accident and Emergency Department, Birmingham Children's Hospital, Birmingham, UK

Correspondence to: Dr K Berry, Accident and Emergency Department, Birmingham Children's Hospital, Steelhouse Lane, Birmingham B4 6NH, UK

kathleen.berry@bhamchildrens.wmids.nhs.uk

\section{REFERENCES}

1 Rumack BH, Peterson RG. Acetaminophen overdose: incidence, diagnosis, and management in 416 patients. Pediatrics 1978:62 (5 pt 2 suppl):898-903.

2 Jones AF, Vale JA. Paracetamol poisoning and the kidney. J Clin Pharm Ther 1993;18:5-8.

3 Keays R, Harrison PM, Wendon JA, et al. Intravenous acetylcysteine in paracetamo induced fulminant hepatic failure: a prospective controlled trial. $B M$ 1991;303:1026-9.

4 Penna A, Buchanan N. Paracetamol poisoning in children and hepatotoxicity. $\mathrm{Br}$ Clin Pharmacol 1991;32:143-9.

5 Peterson RG, Rumack BH. Age as a variable in acetaminophen overdose. Arch Intern Med 1981;141(3 spec no):390-3

6 Bond GR, Krenzelok EP, Normann SA, et al Acetaminophen ingestion in childhood-cos and relative risk of alternative referral strategies. J Toxicol Clin Toxicol $1994 \cdot 32 \cdot 513-25$

7 Department of Trade and Industry. Home and Leisure Accident Surveillance System, 1978-1997. Personal communication, 1999.

8 Bates N, Edwards N, Roper J, et al.

Paediatric toxicology: handbook of poisoning in children. London: Macmillan Reference Limited, 1997.

9 Okonek S, Reinecke HJ. Acute toxicity of pyrazolones. Am J Med 1983;75:94-8.

10 Strong JE, Wilson J, Douglas JF, et al. Phenylbutazone self-poisoning treated by charcoal haemoperfusion. Anaesthesia 1979;34: 1038-40.

11 Berlinger WG, Spector R, Flanigan M, et al. Hemoperfusion for phenylbutazone poisoning. Ann Intern Med 1982;96:334-5.

12 Barke KE, Hough LB. Opiates, mast cells and histamine release. Life Sci 1993;53:1391-9.
13 Wu C, Fry $\mathrm{CH}$, Henry J. The mode of action of several opioids on cardiac muscle. Exp Physiol 1997;82:261-72

14 Hantson P, Evenepoel M, Ziade D, et al. Adverse cardiac manifestations following dextropropoxyphene overdose: can naloxone be helpful? Ann Emerg Med 1995;25:263-6

15 Stork CM, Redd JT, Fine K, et al. Propoxyphene-induced wide QRS complex dysrhythmia responsive to sodium bicarbonate-a case report. J Toxicol Clin Toxicol 1995;33:179-83.

16 Craft AW, Sibert JR. Accidental poisoning in children. Br J Hosp Med 1977:17:469-8.

17 Vertrees JE, McWilliams BC, Kelly HW. Repeated oral administration of activated charcoal for treating aspirin overdose in young children. Pediatrics 1990;85:594-8.

18 Anon. When may eliminating poison save life? Drug Ther Bull 1980;18:41-2.

19 Pond SM. Diuresis, dialysis, and hemoperfusion. Indications and benefits. Emerg Med Clin North Am 1984;2:29-45.

20 Peterson RG, Peterson LN. Cleansing the blood. Hemodialysis, peritoneal dialysis, exchange transfusion, charcoal hemoperfusion, forced diuresis. Pediatr Clin North Am 1986;33:675-89.

21 Good AM, Bateman DN. TOXBASE on the Internet. J Accid Emerg Med 1999;16:399.

\section{Applications are invited for the post of Editor in chief Archives of Disease in Childhood}

$A D C$ is one of the premier journals in paediatrics. We now seek an editor in chief who can increase its scientific and international reputation whilst maintaining its relevance to practising paediatricians worldwide

Applications from generalists or specialists in any branch of paediatrics are inwited. Applications from outside the UK are encouraged and joint applications from two or more individuals willing to act as a team are welcomed.

Full editorial support and training will be provided. The journal will fund any necessary locum requirements. The successful applicant(s) will be free to select hisher own team of associate ecitors and board members. The publishers will provide all support necessary, including perhaps an editor with training in journalism.

Closing date for applications is 15th November 2002. Interviews will be held on 9th December 2002 to enable the successful candidate to take up post early in 2003.

Further details of the post can be discussed with the publishing director, Mrs Alex Williamson. A job description is available on request.

Applications should be sent to Mrs Alex Williamson, BM Publishing Group, BMA House, Tavistock Square, London WC1H 9JR. Tel $\$ 4420$ 7383 6069. Fax +442973836668 email awilliamsonebmjgroup.com
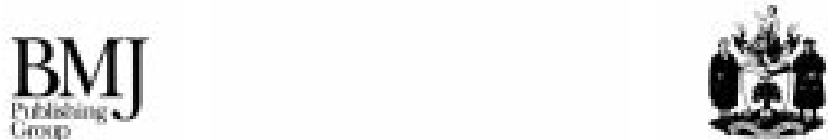